\title{
Bacterias endófitas y su efecto en la inducción de resistencia sistémica en el cultivo de frijol contra Rhizoctonia solani y Fusarium oxysporum
}

\author{
Endophytic bacteria and their effect on the induction of systemic resistance in bean crop \\ against Rhizoctonia solani and Fusarium oxysporum
}

Epifanio Castro-del Ángel, Francisco Daniel Hernández-Castillo*, Gabriel Gallegos-Morales, Yisa María Ochoa Fuentes Departamento de Parasitología. Universidad Autónoma Agraria Antonio Narro. Calzada Antonio Narro 1923, C.P. 25315, Saltillo, Coahuila, México.

\section{RESUMEN}

El cultivo del frijol es afectado por diversas enfermedades en las que destaca la marchitez causada por Rhizoctonia solani y Fusarium spp. El manejo de estos patógenos principalmente se realiza mediante el uso de compuestos químicos los cuales contaminan el ambiente, son tóxicos para el humano, desarrollan resistencia en los fitopatógenos y además aumentan los costos de producción. El objetivo del presente estudio fue evaluar la respuesta de inducción de resistencia mediante la inoculación de bacterias endófitas contra R. solani y F. oxysporum. Se utilizaron plantas de frijol de 45 días de edad para determinar la concentración de proteínas (PR) y la actividad de peroxidasa (POD), fenilalanina amonio liasa (PAL) a las 6,12 , y $24 \mathrm{~h}$ después de la inoculación de los consorcios. Los resultados evidenciaron que los microorganismos endofíticos promueven los mecanismos de defensa en frijol, pudiendo propiciar resistencia contra $F$. oxysporum y R. solani.

Palabras clave: proteínas, peroxidasa, fenilalanina amonio liasa, marchitez del frijol.

\section{ABSTRACT}

Various diseases affect the bean crop, notably the wilt caused by Rhizoctonia solani and Fusarium spp. The management of these pathogens is mainly with the use of chemical compounds, all of which contribute to environmental pollution, are harmful to humans, phytopathogens develop resistance and increase production costs. The objective of this research was to evaluate the resistance induction response by inoculating endophytic bacteria against $R$. solani and $F$. oxysporum. Bean plants of 45 days old were utilized to determine PR protein concentration and the enzymatic activity of peroxidase (POD) and phenylalanine ammonia lyase (PAL) at 6,12 , and $24 \mathrm{~h}$ after consortia inoculation. The results showed that endophytic microorganisms have potential as inducers of defense mechanisms in beans, promoting resistance against $F$. oxysporum and $R$. solani.

Keywords: proteins, peroxidase, phenylalanine ammonium lyase, bean wilt disease.

*Autor para correspondencia: Francisco Daniel Hernández Castillo Correo electrónico: fdanielhc@hotmail.com

\section{INTRODUCCIÓN}

Rhizoctonia solani Kühn (teleomorfo Thanatephorus cucumeris) y Fusarium oxysporum son importantes patógenos comunes de pudrición de la raíz y marchitez del frijol (Phaseolus vulgaris L.) (Oladzad et al., 2019; Abd-El-Khair et al., 2019). En los últimos años, el control biológico se ha convertido en una alternativa prometedora y ecológicamente amigable al control químico en el manejo de enfermedades de las plantas transmitidas por el suelo y se han introducido varios agentes de control biológico como posibles bio-fungicidas (Nasir et al., 2018). Las bacterias endófitas son un grupo de microorganismos endosimbióticos diseminados entre las plantas; una asociación de plantas con bacterias endofíticas incluye una gran diversidad de taxones bacterianos y plantas hospedadoras (Tamosiune et al., 2017). Investigaciones recientes han identificado especies bacterianas endofíticas y se ha informado cada vez más que reducen el crecimiento y la actividad de una plétora de fitopatógenos (Latha et al., 2019). Las bacterias endofíticas pueden desempeñar un papel importante en el desarrollo de la mejora del crecimiento de las plantas, la fitorremediación, la solubilización de fosfatos, la fijación de nitrógeno, la modulación del metabolismo de las plantas y la señalización de fitohormonas que conducen a la adaptación del estrés biótico/abiótico ambiental (Muthukumar et al., 2017). Indirectamente, las bacterias endofíticas pueden mejorar la salud de las plantas al atacar las plagas y patógenos con antibióticos, enzimas hidrolíticas, limitación de nutrientes y cebar las defensas de las plantas. Para conferir estos beneficios, las bacterias deben colonizar la endosfera de la planta después de colonizar la rizosfera (Afzal et al., 2019). La inducción de resistencia se asocia a las proteínas relacionadas con la patogenia (proteínas PR) como grupo de las proteínas antifúngicas relacionadas con la defensa inducibles más importantes, que incluyen defensinas, tioninas, proteínas similares a la osmotina, proteínas similares a la taumatina, quitinasas, glucanasas, oxalato oxidasa o proteínas similares a la oxalato oxidasa y proteínas de transferencia de lípidos (Moosa et al., 2017). La fenilalanina amonio liasa (Phenylalanine ammonia-lyase; PAL) cataliza el primer paso en la vía biosintética del fenilpropanoide a través de la desaminación de la fenilalanina en ácido transcinámico, un precursor de las vías biosintéticas de la lignina y los flavonoides. (Jun et al., 2018, Gho et al., 2020). La PAL juega un efecto

Volumen XXIII, Número 3 
importante en la síntesis de metabolitos secundarios y el proceso de resistencia al estrés (Zhen y DeGang, 2017). Otro del grupo de enzimas importantes en la defensa de las plantas son las peroxidasas; antioxidantes clave, están ampliamente distribuidas en la naturaleza y catalizan la oxidación de varios sustratos donantes de electrones concomitante con la descomposición del $\mathrm{H}_{2} \mathrm{O}_{2}$ (Pandey et al., 2017). GutiérrezMartínez et al. (2020) reportan que la actividad enzimática en hojas de frijol, hubo un aumento en todas las concentraciones con cadmio y sugieren que podría deberse a la inducción de mecanismos de señalización sistemática provocados por el estrés oxidativo como medio de protección de las hojas. El aumento en las actividades de POD en peras inoculadas con B. amyloliquefaciens indican su capacidad para inducir la defensa bacteriana a través de enzimas relacionadas con la defensa (Pingping et al., 2017). El objetivo del presente estudio fue evaluar la respuesta de inducción de resistencia mediante la inoculación de bacterias endófitas contra $R$. solani y F. oxysporum.

\section{MATERIALES Y MÉTODOS}

Aislamiento e identificación de los hongos fitopatógenos Se recolectaron plantas de frijol con síntomas de marchitez y necrosis de raíz y tallos por Rhizoctonia solani y Fusarium sp., las raíces y tallos se lavaron con agua corriente, las cuales se secaron bajo campana de flujo laminar durante 12 horas. Se cortaron porciones de tejido sano y enfermo, y se desinfectaron externamente con hipoclorito de sodio al 3\%, lavándose tres veces consecutivas con agua destilada estéril para eliminar el exceso de desinfectante. Posteriormente, se colocaron en toallas estériles para secarse. Los fragmentos de raíces y tallos fueron sembrados en medio de cultivo PDA (BD, Bioxon, Dickinson and Company, México) y se incubaron en una incubadora (Lumistell ${ }^{\mathrm{MR}}$ IEC- 41 , México) a $26 \pm 2^{\circ} \mathrm{C}$ por siete días. F. oxysporum fue identificado fenotípicamente de acuerdo con las características morfológicas descritas por Leslie y Summerell (2006); la identificación de $R$. solani se determinó por los criterios de Sneh et al. (1991). Se utilizó el método de cultivos monospóricos para la purificación de $F$. oxysporum y punta de hifa para el caso de $R$. solani, los aislamientos fueron conservados bajo refrigeración en agar inclinado a $4{ }^{\circ} \mathrm{C}$.

\section{Corroboración molecular de los hongos Extracción de ADN de los hongos}

Cepas axénicas de los hongos desarrollados en medio de cultivo PDA de siete días de edad, se rasparon con la ayuda de una espátula para la obtención de micelio. La extracción fue realizada por el método de Nicholson et al. (2001), usando buffer que contenía EDTA $10 \mathrm{mM}$, Tris $\mathrm{HCl} 10 \mathrm{mM} \mathrm{pH}$ 8.0, SDS $0.5 \%$. El ADN extraído fue resuspendido en $25 \mu \mathrm{L}$ de TE. La integridad y calidad del ADN se verificó en gel de agarosa al $1 \%$, bajo electroforesis horizontal aplicando un voltaje de 100 volts por $40 \mathrm{~min}$.

\section{Amplificación por reacción en cadena de la polimerasa (PCR)}

Se amplificó la región ITS1 e ITS4 (Internal Transcribed Spacer), mediante una mezcla de amplificación en volumen final de $20 \mu \mathrm{L}$, compuesto por $13.58 \mu \mathrm{L}$ de agua $\mathrm{MQ}, 2.0 \mu \mathrm{L}$ de buffer $\mathrm{MgCl}(10 \mathrm{X}), 0.32 \mu \mathrm{L}$ de $\mathrm{MgCl}_{2}(25 \mathrm{mM}), 0.4 \mu \mathrm{L}$ de dNTP's (10mM), 0.5 $\mu \mathrm{L}$ de cada iniciador ITS1 (5'TCC GTA GGT GAA CCT GCG G3') e ITS4 (5'TCC TCC GCT TAT TGA TAT GC3') (10 $\mu \mathrm{M}), 0.5 \mu \mathrm{L}$ de DMSO, $0.2 \mu \mathrm{L}$ de ADN Taq-polimerasa $1 \mathrm{U}$ y $1 \mu \mathrm{L}$ de ADN (40 ng/ $\mu \mathrm{L})$. Las reacciones de amplificación se efectuaron usando un termociclador (Bio-Rad $\mathrm{T}_{100^{\mathrm{TM}}}$ Thermal Cycler California USA) bajo el siguiente programa: 1 ciclo de $94^{\circ} \mathrm{C} 3$ min, seguido de 35 ciclos a $94^{\circ} \mathrm{C}$ por $45 \mathrm{~s}, 53^{\circ} \mathrm{C}$ por 45 s y $72^{\circ} \mathrm{C} 1 \mathrm{~min}$; finalizando con un ciclo de polimerización de $72{ }^{\circ} \mathrm{C}$ por $7 \mathrm{~min}$. Las bandas amplificadas se observaron en un gel de agarosa al 1.0\% a $90 \mathrm{~V}$ por $60 \mathrm{~min}$ (Nicholson et al., 2001).

\section{Secuenciación de productos de PCR}

Los productos de PCR fueron incrementados y purificados por medio de kit GeneAll'Expin ${ }^{\top M}$ PCR SV, y se secuenciaron por el laboratorio Macrogen Online Sequencing Order System (Rockville, MD, United States), las secuencias obtenidas, se analizaron en la base de datos del GenBank del National Center for Biotechnology Information (NCBI), usando el programa BLAST (Basic Local Aligment Search Tool) para secuencias altamente similares. Cada secuencia obtenida se le depuró la parte inicial y final para aumentar la sensibilidad del análisis (Castro del Ángel et al., 2019).

\section{Bacterias endófitas}

Dos aislamientos de Bacillus amyloliquefaciens cepa 53 y $B$. amyloliquefaciens cepa 21 fueron tomadas de la colección de microorganismos del laboratorio de Fitopatología de la Universidad Autónoma Agraria Antonio Narro. Con estos aislamientos se formaron dos consorcios: uno a una concentración de $1 \times 10^{6}$ ufc y otro de $1 \times 10^{8}$ ufc.

\section{Formación de consorcios}

Se determinó la compatibilidad entre las cepas que mostraron los niveles más altos de antagonismo y mantuvieron su acción continua sobre los fitopatógenos. La compatibilidad se realizó en placas de Petri considerando el antagonismo solo y combinado de las cepas de bacterias endófitas desarrollando la ecuación de Sueke et al. (2010), se consideró la siguiente expresión matemática: , donde: Efecto $A=$ Efecto en $A$ cuando es probado en combinación de $B$ / Efecto en $A$ solo y Efecto $B=$ Efecto en $B$ cuando es probado en combinación de a / Efecto en B solo. La aceptación del efecto fue a partir de los siguientes posibles resultados en la mezcla: $\leq 0.5$, sinergismo; $0.5-1.0$, aditivo; $1.0-4.0$, indiferencia $y>4$, antagonismo.

\section{Microorganismos y condiciones de cultivo}

El inóculo bacteriano se preparó con una asada de las cepas 21 y 53, ambas se cultivaron en medio líquido papa 
dextrosa (PD) y se incubaron en un agitador rotatorio (Labnet, Orbit 1000, USA) a $120 \mathrm{rpm}$ a $26 \pm 2{ }^{\circ} \mathrm{C}$ durante siete días. Después de la incubación, las esporas se recuperaron mediante centrifugación en una centrifuga (Clay Adams Dynac II Centrifuge, United States) a 3500 rpm y se resuspendieron en agua destilada estéril; la suspensión se ajustó en una cámara de Neubauer, la concentración utilizada fue $1 \times 10^{6} \mathrm{ufc} / \mathrm{mL}$ y $1 \times 10^{8}$ ufc $/ \mathrm{mL}$. Las suspensiones de los endófitos se conservaron en refrigeración a $4{ }^{\circ} \mathrm{C}$ durante $24 \mathrm{~h}$.

Los conidios de $F$. oxysporum se recuperaron raspando la placa de Petri y suspendiéndolos en $500 \mathrm{~mL}$ de agua destilada estéril, y finalmente se ajustó a $1 \times 10^{6}$ conidios $/ \mathrm{mL}$. El inóculo de $R$. solani se obtuvo mediante la metodología de Schneider et al. (1997) modificada; se colocaron $300 \mathrm{~g}$ de grano de trigo en matraces de $1000 \mathrm{~mL}$ con $100 \mathrm{~mL}$ de medio PD y se esterilizaron en autoclave durante 30 min por tres días consecutivos. Los matraces se inocularon con tres discos de $5 \mathrm{~mm}$ de diámetro con micelio del patógeno de siete días de edad, los cultivos se incubaron a $22 \pm 2{ }^{\circ} \mathrm{C}$ durante 21 días.

\section{Establecimiento del ensayo}

Semillas de frijol (Phaseolus vulgaris CV. Pinto Saltillo) se sembraron en macetas de $5 \mathrm{Kg}$ de capacidad con suelo pasteurizado, recolectado de parcelas donde anteriormente se había cultivado frijol, el método utilizado fue pasteurización que consistió someter el suelo a $80^{\circ} \mathrm{C}$ en autoclave durante 3 veces consecutivas y dejando enfriar entre cada vez. Al momento de la siembra se realizó la inoculación de los fitopatógenos; para el caso de F. oxysporum con una suspensión de $1 \times 10^{6}$ conidios $/ \mathrm{mL}$; para $R$. solani 10 semillas de trigo con esclerocios y micelio de $R$. solani de 21 días de edad. Los tratamientos estudiados se reportan en la tabla 1. Los consorcios se inocularon tres veces: una al momento de la siembra, la segunda a los 25 días después de la emergencia y la tercera a los 45 días después de la emergencia. Es importante mencionar que los experimentos se establecieron por separado, es decir un ensayo para F. oxysporum y otro para $R$. solani. Los consorcios son una mezcla de especies de Bacillus: la diferencia entre estos consiste en dos niveles de inóculo en cada uno de ellos. El experimento se estableció en un diseño de bloques al azar bajo condiciones de invernadero con siete repeticiones por cada tratamiento, una maceta fue considerada una repetición que contó con dos plantas de frijol.

\section{Determinación de actividad enzimática}

El material vegetal utilizado para la extracción consistió en $1 \mathrm{~g}$ de hojas de frijol de 45 días de edad, previamente lavadas y secas, se maceraron en mortero con una solución amortiguadora de fosfatos pH $7.30 .1 \mathrm{M}$, relación 1:2 (m/v). Posteriormente las muestras se centrifugaron a $12500 \mathrm{rpm}$ durante $15 \mathrm{~min}$ a $4{ }^{\circ} \mathrm{C}$, el sobrenadante fue separado para la determinación de la concentración de proteínas (PR), y actividad de fenilalanina amonio liasa (PAL) y peroxidasa (POD). La inoculación de los consorcios se realizó mediante aplicación a la raíz utilizando un aspersor manual (Truper 10929, México) de 1 L de capacidad y la inoculación de los
Tabla 1. Designación de tratamientos en el cultivo de frijol en condiciones de invernadero

Table 1. Treatments designation in bean crop under greenhouse conditions.

\begin{tabular}{llc}
\hline Código & Tratamiento & Concentración \\
\hline Cons 1 + F. oxysporum & (T1) Patógeno + consorcio 1 & $1 \times 10^{6}$ ufc \\
Cons 2 + F. oxysporum & (T2) Patógeno + consorcio 2 & $1 \times 10^{8}$ ufc \\
Cons 1 & (T3) Consorcio 1 & $1 \times 10^{6}$ ufc \\
Cons 2 & (T4) Consorcio 2 & $1 \times 10^{8}$ ufc \\
Patógeno & (T5) Fusarium oxysporum & $1 \times 10^{6}$ conidios $/ \mathrm{mL}$ \\
Testigo & (T6) Testigo & Agua \\
\hline Cons 1 + R. solani & (T1) Patógeno + consorcio 1 & $1 \times 10^{6}$ ufc \\
Cons 2 + R. solani & (T2) Patógeno + consorcio 2 & $1 \times 10^{8}$ ufc \\
Cons 1 & (T3) Consorcio 1 & $1 \times 10^{6}$ ufc \\
Cons 2 & (T4) Consorcio 2 & $1 \times 10^{8}$ ufc \\
Patógeno & (T5) Rhizoctonia solani & 10 semillas de trigo/ \\
maceta
\end{tabular}

hongos fitopatógenos se llevó a cabo con una jeringa hipodérmica con aplicación de $25 \mathrm{~mL}$ al suelo (Castro del Ángel et al., 2019). Las muestras se colectaron a las $0,6,12$ y $24 \mathrm{~h}$ después de la aplicación de los tratamientos, las muestras en el tiempo de $0 \mathrm{~h}$ fueron colectadas antes de la inoculación (González-Gallegos et al., 2015), el ensayo se desarrolló por triplicado.

\section{Cuantificación de proteínas (PR)}

Se determinó según el método de Bradford, utilizando como patrón albúmina de suero bovino (Bradford, 1957). Para la preparación del reactivo Bradford. Se pesaron $10 \mathrm{mg}$ de azul de Coomassie G-250, se adicionaron $5 \mathrm{~mL}$ de etanol al $95 \%$ v/v y $10 \mathrm{~mL}$ de ácido fosfórico al $85 \% \mathrm{v} / \mathrm{v}$ y se aforó a $100 \mathrm{~mL}$ con agua destilada, esta solución se filtró con papel Whatman No. 2 y se almacenó en frasco ámbar a $4{ }^{\circ} \mathrm{C}$.

\section{Preparación de la solución concentrada de albúmina sérica bovina (BSA) $1000 \mu \mathrm{g} / \mathrm{mL}$.}

Se disolvieron $4 \mathrm{mg}$ de BSA en $4 \mathrm{~mL}$ de agua destilada y se homogeneizó la solución. Después, se hizo una curva de calibración a partir de diferentes concentraciones de BSA, las soluciones se prepararon con concentración de 100-1000 $\mu \mathrm{g} / \mathrm{mL}$, a partir de BSA y agua destilada (Buffer), llevándolas a un volumen final $1 \mathrm{~mL}$.

\section{Determinación de proteínas por la técnica de Bradford}

Se mezclaron en un tubo de vidrio $100 \mu \mathrm{L}$ de cada una de las concentraciones de BSA con $5 \mathrm{~mL}$ de reactivo de Bradford, después de 5 minutos se realizó la lectura en el espectrofotómetro (Jenway 7305 Spectrophotometer, UK) a una longitud de onda de $595 \mathrm{~nm}$, ajustando el cero de absorbancia con el blanco. 
Partiendo de la Ley de Beer-Lamber, se realizó una curva ordenando en el eje $X$ las concentraciones y en el eje $Y$ las absorbancias, luego se realizó la regresión lineal y se obtuvo la ecuación $Y=m x+b$ y el $R^{2}$.

\section{Determinación de la actividad de fenilalanina amonio liasa (PAL)}

Se tomaron $0.9 \mathrm{~mL}$ de L-Fenilalanina $1 \mathrm{mg} / \mathrm{mL}$, se adicionó $0.1 \mathrm{~mL}$ de extracto enzimático e incubó a $40^{\circ} \mathrm{C}$ durante 30 min en un termociclador (Bio-Rad $\mathrm{T}_{100^{\mathrm{TM}}}$ Thermal Cycler, California USA) a $300 \mathrm{rpm}$. La reacción se detuvo con 0.25 $\mathrm{mL}$ de ácido clorhídrico $5 \mathrm{~N}$. Las muestras se colocaron en baño de hielo y se les adicionó $5 \mathrm{~mL}$ de agua destilada. Los valores de absorbancia se determinaron a una $\lambda=290 \mathrm{~nm}$ en un espectrofotómetro (Jenway 7305 Spectrophotometer, UK) y se calculó con un coeficiente de extinción molar de 17.4/mM/cm (Trotel et al., 2007). Una unidad de actividad enzimática se definió como equivalente a la producción de 1 $\mu \mathrm{mol}$ de ácido transcinámico producido por minuto por mg de proteína (Rodríguez et al., 2006).

\section{Determinación de la actividad de peroxidasa (POD)}

El ensayo fue realizado en un espectrofotómetro (Jenway 7305 Spectrophotometer, UK) a $610 \mathrm{~nm}$ usando rojo de fenol como sustrato, el volumen total de la reacción fue de 1 $\mathrm{mL}$ a $37^{\circ} \mathrm{C}$. A $20 \mu \mathrm{L}$ del extracto enzimático se le adicionaron $50 \mu \mathrm{L}$ de rojo de fenol al $0.2 \%(\mathrm{~m} / \mathrm{v}), 930 \mu \mathrm{L}$ de solución amortiguadora de citrato de sodio $\mathrm{pH} 4.2,50 \mathrm{mM}$. La reacción dió inicio con $10 \mu \mathrm{L}$ de peróxido de hidrogeno $1 \mathrm{mM}$, dejando transcurrir $3 \mathrm{~min}$, para detener la reacción se adicionaron 40 $\mu \mathrm{L}$ de hidróxido de sodio $2 \mathrm{~N}$. La absorbancia se registró a 610 $\mathrm{nm}$ y se calculó con un coeficiente de extinción molar de 22 $000 \mathrm{M} / \mathrm{cm}$, para el producto oxidado. Se expresó la actividad de peroxidasa como milimoles de rojo de fenol que se oxidan por gramo de tejido fresco por minuto (Yedidia et al., 1999).

\section{Análisis estadístico}

Las medias obtenidas de la concentración de proteína y de la actividad enzimática fueron sometidas a un análisis de varianza y prueba de separación de medias por el método de prueba de rangos múltiples de Tukey al 0.05 de significancia en el programa SAS versión 9.0 para Windows.

\section{RESULTADOS Y DISCUSIÓN}

\section{Aislamiento e identificación de los hongos fitopatógenos}

Las cepas de hongos aisladas de plantas de frijol con síntomas de marchitez y pudrición de raíz fueron identificadas por características morfológicas. Se observó micelio algodonoso con tonos purpuras a partir de los cuatro días de edad, las características microscópicas fueron microconidios sin septos, ovales, elípticos a reniformes (Khan et al., 2021). Las clamidosporas de posición intercalar y terminal, individualmente o en pares, con una apariencia lisa circular de doble pared. Las macroconidias observadas eran fusoides y alantoides con tres a cinco septos y en forma de gancho (Figura 1A) las características observadas corresponden a versal cerca de la unión, estas características corresponden a las reportadas por (Sneh et al., 1991 y Al-Fadhal et al., 2019), se pueden observar en la Figura 1B.

\section{Corroboración molecular de los hongos}

La confirmación de la identificación morfológica de las especies se obtuvo mediante secuenciación de la región intergénica ITS1 e ITS4, las secuencias obtenidas comparadas en BLAST dieron como resultado a Fusarium oxysporum con clave de acceso JN624887, máximo score de 915, y Rhizoctonia solani con clave de acceso JX050236.1 y máximo score

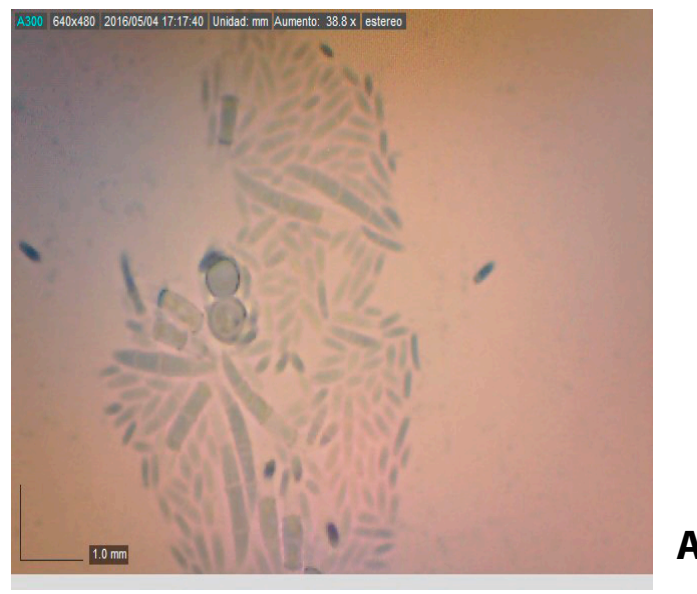

A

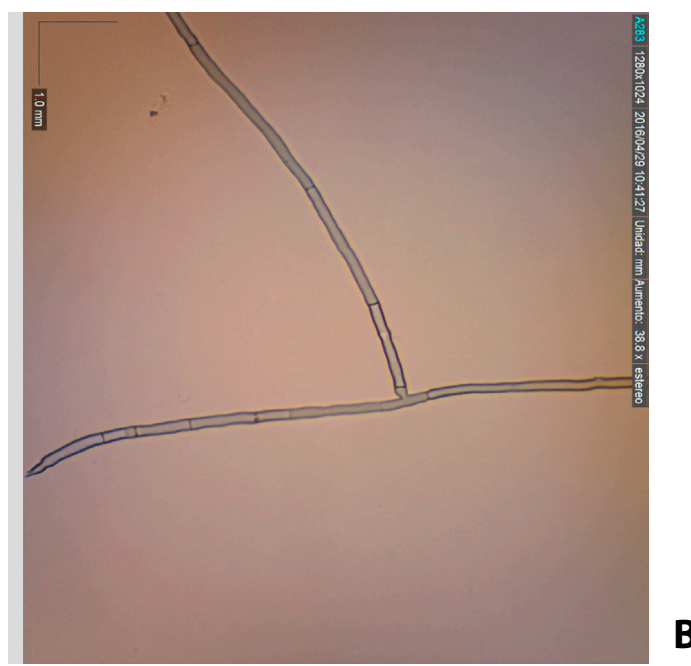

Figura 1. Estructuras morfológicas de Fusarium oxysporum desarrollado en medio clavel agar (A) y crecimiento de Rhizoctonia solani en medio PDA (B).

Figure 1. Morphological structures of Fusarium oxysporum grown on carnation agar medium $(\mathrm{A})$ and Rhizoctonia solani grown on PDA medium (B).

las reportadas por Leslie y Summerell (2006) para Fusarium oxysporum. Las características consideradas para la identificación de Rhizoctonia solani fueron observadas como micelio incoloro a los primeros 3 días de desarrollo, pero se volvió amarillento a color marrón claro a las dos semanas de edad, con células alargadas y ramificaciones que crecieron en ángulos aproximadamente rectos a la hifa principal, estaban ligeramente constreñidos en la unión, y con una pared trans- 
de 1216, ambas con $99 \%$ de identidad (Tabla 2). Singha et al. (2016) identificaron molecularmente aislados de Fusarium amplificando la región del espaciador transcrito interno (ITS) del ADN ribosómico conservado utilizando los cebadores ITS1 e ITS4. Todas las secuencias de ITS se compararon en busca de espacios y similitudes. Por otra parte, Basbagci et al. (2019) identificó aislamientos de $R$. solani morfológicamente y los corroboró mediante secuenciación de la región ITS1 e ITS4 a partir de ADN genómico.

Tabla 2. Claves de accesos de la corroboración molecular de las cepas fúngicas.

Table 2. Access codes of the molecular corroboration of the fungal strains.

\begin{tabular}{ccc}
\hline Cepa & NCBI & Código de acceso \\
\hline F. oxysporum & Fusarium oxysporum strain Af/8/1 & JN624887 \\
R. solani & Rhizoctonia solani isolate JZB-34 & JX050236.1 \\
\hline
\end{tabular}

\section{Formación de los consorcios}

La evaluación en cultivo dual permitió conocer que entre las cepas de bacterias endófitas no existió antagonismo entre ellas al evaluarlas simultáneamente sobre los hongos en estudio (Figura 2). El efecto combinado de $B$. amyloliquefaciens cepa 53 y B. amyloliquefaciens cepa 21 contra $F$. oxysporum fue de 2.06 mientras que para $R$. solani fue de 1.98, de acuerdo con Sueke et al. (2010) el efecto encontrado fue nulo, es decir no existió antagonismo, ni sinergismo entre cepas, sin embargo, fueron seleccionadas para ser evaluadas en el cultivo de frijol en diferente tamaño de inóculo. En otro contexto, Yanti et al. (2021), reportan consorcios de Bacillus como inductores del crecimiento vegetal en el cultivo de tomate, al respecto, estos autores seleccionaron los consorcios más prometedores por métodos cualitativos observando la zona de inhibición entre ellos en presencia de Sclerotium rolfsii.

\section{Determinación de actividad enzimática}

Los tratamientos indujeron la actividad proteica de los sistemas ensayados. La actividad mostrada en plantas de frijol, con respuesta a F. oxysporum y $R$. solani se ve incrementada a partir de las $6 \mathrm{~h}$ en todos los tratamientos, mostrando una tendencia a disminuir con el paso de las horas. Las

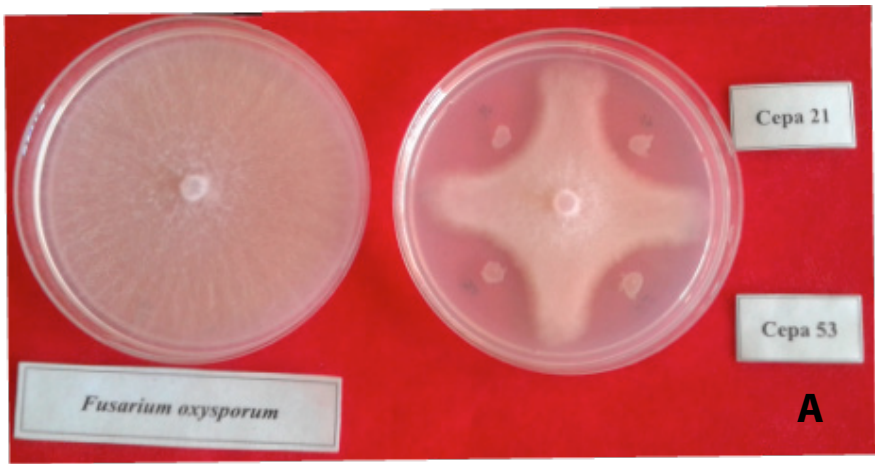

plantas con exposición directa a F. oxysporum muestran los valores más altos de proteína, sin embargo la exposición del consorcio 2 no presenta diferencia significativa frente a este. A las doce horas las plantas inoculadas con los consorcios 1 y 2 e inoculados simultáneamente con $F$. oxysporum muestran la actividad más alta en comparación con el tratamiento individual de $F$. oxysporum $(\mathrm{P}<0.0001)$, lo que demuestra que se está expresando la respuesta de defensa de la planta frente al patógeno por la acción de los consorcios bacterianos aplicados. Por otra parte, las plantas coinoculadas con el consorcio 2 y el patógeno, se mantiene la actividad constante desde las $6 \mathrm{~h}$ y hasta las $24 \mathrm{~h}$ mientras que el consorcio 1 la actividad declina a partir de la $12 \mathrm{~h}$ de estudio. Los consorcios 1 y 2 en ausencia del patógeno también inducen la actividad proteica en comparación al testigo absoluto $(P<0.0001)$. La actividad de proteína debe formar parte del mecanismo de defensa de la planta de frijol, y es la responsable de la inducción de resistencia desarrollada por la planta después del tratamiento con los consorcios y la infección por el patógeno. La inducción de resistencia se asocia a las proteínas relacionadas con la patogenia (proteínas PR) como grupo de las proteínas antifúngicas relacionadas con la defensa inducibles más importantes, que incluyen defensinas, tioninas, proteínas similares a la osomtina, proteínas similares a la taumatina, quitinasas, glucanasas, oxalato oxidasa u proteínas similares a la oxalato oxidasa y proteínas de transferencia de lípidos (Moosa et al., 2017). La inducción y acumulación de proteínas PR protegen a las plantas de futuras infecciones, su activación es muy importante, ya que son un componente indispensable de las respuestas inmunitarias innatas en plantas en condiciones de estrés biótico o abiótico (Jain y Khurana, 2018).

\section{Determinación de la actividad enzimática de PAL}

Los mayores niveles de actividad se expresaron en las plantas tratadas con los consorcios 1 y 2 en presencia de $F$. oxysporum a los diferentes tiempos de muestreo $(P<0.0001)$, por ello se puede considerar que los consorcios estimulan la defensa de la planta ante al patógeno encontrándose los valores más significativos en los tratamientos antes mencionados. El incremento en la actividad de PAL de la vía de los fenilpropanoides aumenta la producción de ácido transcinámico a partir de fenilalanina, el cual es trasformado a través

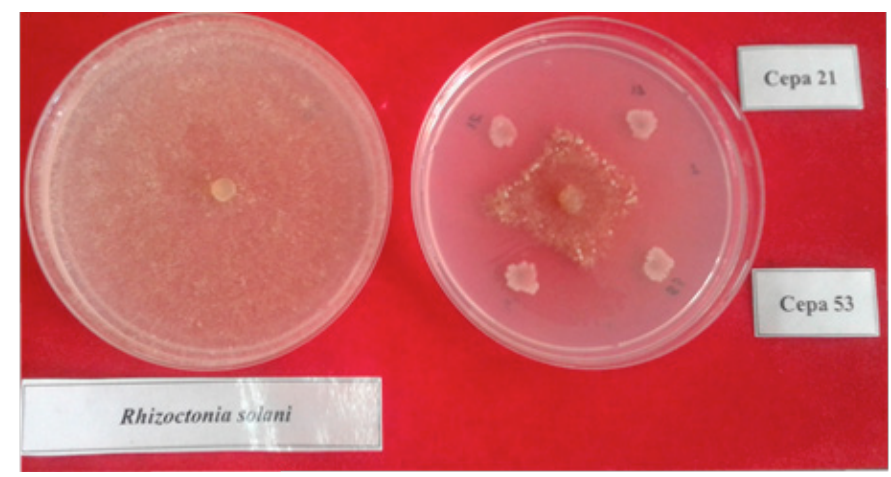

Figura 2. Inhibición in vitro de Fusarium oxysporum (A) y Rhizoctonia solani desarrollado en medio PDA (B).

Figure 2. In vitro inhibition of Fusarium oxysporum (A) and Rhizoctonia solani grown in PDA medium (B). 
de otras dos reacciones enzimáticas hasta paracumaril $\mathrm{CoA}_{i}$ precursor de un amplio grupo de productos que incluyen la lignina, los fenilpropenos y los flavonoides (Glas et al., 2012). Ardila et al. (2007) reportaron que la actividad PAL se activa a partir de las $6 \mathrm{~h}$ postinoculación de Fusarium oxysporum f.sp. dianthi raza 2 en plantas de clavel, encontrándose los picos máximos a las $12 \mathrm{~h}$ y disminuyó a las $24 \mathrm{~h}$, sin embargo, en este ensayo los valores más altos de PAL se obtuvieron hasta las $24 \mathrm{~h}$. Al respecto Duba et al. (2019) reportaron que la actividad PAL inmediatamente y $24 \mathrm{~h}$ después de la inoculación, en líneas de trigo evaluadas fue significativamente $(p \leq 0.01)$ mayor en plantas inoculadas con F. culmorum. Singh et al. (2020) con inoculaciones de Trichoderma asperellum y ácido ascórbico en semillas de tomate, las plantas tratadas mostraron una mayor acumulación de contenido total de fenol y una mayor actividad PAL, POD, quitinasa y polifenol oxidasa en comparación con las plantas no tratadas. En otro apartado, la determinación de PAL en plantas de frijol contra R. solani; en todos los tratamientos existe incremento en la actividad enzimática desde las $6 \mathrm{~h}$ hasta las $24 \mathrm{~h}$ en comparación con el testigo. Se encontró que los consorcios 1 y 2 sin inoculación del patógeno, son mayores que el testigo libre de cualquier tratamiento, lo que se relaciona con un posible cambio en la activación de mecanismos de defensa que generan los consorcios aplicados sobre plantas de frijol antes de que se inocule el patógeno. La capacidad de los hongos patógenos para inducir resistencia sistémica está determinada por la actividad de la fenilalanina amonio liasa, relacionada con el metabolismo de los compuestos fenólicos, la vía metabólica de las fitoalexinas y la inducción de la síntesis de ácido salicílico (SA). En la vía de biosíntesis de SA, el ácido corísmico se convierte en SA a través de la fenilalanina. El ácido cinámico se convierte en productos intermedios de PAL y luego se convierte en SA. El ácido salicílico es un mensajero secundario en el proceso de inducir resistencia al estrés biótico en las plantas (Barna et al., 2012). La PAL cataliza el primer paso en la vía biosintética del fenilpropanoide a través de la desaminación de la fenilalanina en ácido transcinámico, un precursor de las vías biosintéticas de la lignina y los flavonoides. (Jun et al., 2018, Gho et al., 2020). La PAL juega un efecto importante en la síntesis de metabolitos secundarios y el proceso de resistencia al estrés (Zhen y DeGang, 2017). Por su parte, Rais et al. (2017) estudiaron rizobacterias para la inducción de diferentes vías en plantas de arroz a través de la producción de varios metabolitos. Reportan, que Bacillus spp. inducen enzimas como la superóxido dismutasa, peroxidasa, polifenol oxidasa y fenilalanina amonia-liasa contra la infección por Pyricularia oryzae. Como se observa en este trabajo, la inducción de esta enzima por los consorcios puede ser relevante en los mecanismos de defensa de las plantas de frijol a las enfermedades.

\section{Determinación de la actividad enzimática de POD.}

La expresión de la actividad de POD en plantas de $P$. vulgaris no presenta diferencias significativas ante los diferentes tratamientos que se aplicaron, en los diferentes tiempos a los que se realizó el ensayo. Sin embargo, a las 12 y $24 \mathrm{~h}$ de muestreo las plantas tratadas con los consorcios en ausencia de $R$. solani presentan mayor actividad de POD en comparación a las plantas sin ningún tratamiento. En adición se puede observar que a las $6 \mathrm{~h}$ el testigo absoluto presenta aumento en la actividad POD, pero el incremento de la actividad peroxidasa, que se detecta en las plantas libres de cualquier tratamiento, es posiblemente debido al efecto de la herida que se hace, pues dicha actividad no progresa a través del tiempo. Por otra parte, Ezziyyani et al. (2005) reportan que a las 24 y 96 horas postaplicación, se produce un incremento de actividad peroxidasa y que la actividad aumenta con el tiempo posterior a la inoculación. La mayor actividad se da a las $96 \mathrm{~h}$ en plantas tratadas con T. harzianum. Por lo tanto, Shoaib et al. (2019) asumen que la supresión de Sclerotium rolfsii está directamente relacionada con el aumento de la actividad de las enzimas peroxidasa, catalasa, polifenol oxidasa y fenilalanina amonio liasa, por lo que proporciona la base para la resistencia en garbanzo. En otro contexto, Khanna et al. (2019) sugieren que los aspectos favorables de Pseudomonas aeruginosa y Burkholderia gladioli en la modulación de las características de crecimiento y la expresión de defensa antioxidante de Lycopersicon esculentum para enfrentar el estrés oxidativo generado bajo la infección por nemátodos. A su vez, Sahni y Prasad (2020) indican que Pseudomonas sp. y vermicomposta aplicadas simultáneamente las actividades de las enzimas POD y PAL fueron altas en las plantas de garbanzo después de inocularse con $S$. rolfsii. Sus actividades máximas aparecieron a las $48 \mathrm{~h}$ después de la exposición al patógeno.

\section{CONCLUSIONES}

Se identificó a F. oxysporum y $R$. solani como agentes causales de marchitez y pudrición de raíz de frijol variedad Pinto Saltillo. Los consorcios de bacterias endófitas provocaron un aumento en la concentración de proteínas y actividad enzimática en el cultivo de frijol, como mecanismo de defensa contra F. oxysporum y R. solani a partir de las 6 horas bajo condiciones de invernadero. La mayor actividad de PAL aumenta significativamente a las $24 \mathrm{~h}$ postinoculación, por lo que la PAL contribuye al mecanismo de resistencia del frijol al aumentar su actividad después de la inoculación con los consorcios bacterianos. Como estudios posteriores se pretende trabajar con más tiempos de exposición de los tratamientos y más muestreos de actividad enzimática y así mismo determinar otras enzimas implicadas en la defensa vegetal por la vía de resistencia sistémica inducida.

\section{REFERENCIAS}

Abd-El-Khair, H., Elshahawy, I.E., Haggag, H.E.K. 2019. Field application of Trichoderma spp. combined with thiophanate-methyl for controlling Fusarium solani and Fusarium oxysporum in dry bean. Bulletin of the National Research Centre. 43(1): 1-9. https://doi.org/10.1186/s42269019-0062-5 
Al-Fadhal, F.A., AL-Abedy, A.N., Alkhafije, D.A. 2019. Isolation and molecular identification of Rhizoctonia solani and Fusarium solani isolated from cucumber (Cucumis sativus L.) and their control feasibility by Pseudomonas fluorescens and Bacillus subtilis. Egyptian Journal of Biological Pest Control. 29(47):111. https://doi.org/10.1186/s41938-019-0145-5

Ardila, H., Baquero, B., Martínez, S. 2007. Inducción de la actividad de la enzima fenilalanina amonio liasa en clavel (Dianthus caryophyllus L.) por elicitores del hongo Fusarium oxysporum f. sp. dianthi raza 2. Revista Colombiana de Química. 36(2): 151-167. Disponible en: https://www. scielo.org.co/scielo.php?script=sci_arttext\&pid=S012028042007000200002\&lng=en\&nrm=iso

Afzal, I., Shinwari, Z.K., Sikandar, S., Shahzad, S. 2019. Plant beneficial endophytic bacteria: Mechanisms, diversity, host range and genetic determinants. Microbiological Research. 221:36-49. https://doi.org/10.1016/j.micres.2019.02.001

Barna, B.; Fodor, J.; Harrach, B.D.; Pogány, M.; Király, Z. 2012. The Janus face of reactive oxygen species in resistance and susceptibility of plants to necrotrophic and biotrophic pathogens. Plant Physiology Biochemistry. 59:37-43.https:// doi.org/10.1016/j.plaphy.2012.01.014

Basbagci, G., Unal, F., Uysal, A., Dolar, F. S. 2019. Identification and pathogenicity of Rhizoctonia solani AG-4 causing root rot on chickpea in Turkey. Spanish Journal of Agricultural Research. 17(2) e1007:1-12. https://doi.org/10.5424/sjar/201917213789

Bradford. 1976. A rapid and sensitive method for the quantitation of microgram quantities of protein utilizing the principle of protein-Dye Binding. Analytical Biochemistry. 72: 248-254. https://doi.org/10.1006/abio.1976.9999

Castro del Ángel, E., Hernández Castillo, F. D., Gallegos Morales, G., Ochoa Fuentes, Y. M., Castillo Reyes, F. 2019. Biocontrol of Rhizoctonia solani and Fusarium oxysporum with endophytic bacteria formulations and its effect in the growth promotion in bean crop. Revista Bio Ciencias 6 (e416). 1-13. https://doi. org/10.15741/revbio.06.e416

Duba, A., Goriewa-Duba, K., Wachowska, U., Głowacka, K., Wiwart, M. 2019. The associations between leaf morphology, phenylalanine ammonia lyase activity, reactive oxygen species, and Fusarium resistance in selected species of wheat with different ploidy levels. Plants. 8: 360: 1-19. https://doi. org/10.3390/plants8100360

Ezziyyani, M., Requena, M. E.y Candela, M. E. 2005. Producción de proteínas-PR en la inducción de resistencia a Phytophthora capsici en plantas de pimiento (Capsicum annuum L.) tratadas con Trichoderma harzianum. Anales de Biología. 27: 143-153. Disponible en: https://revistas.um.es/analesbio/ article/view/29941

González-Gallegos, E., Laredo-Alcalá, E., Ascacio-Valdés, J., Jasso de Rodríguez, D., Daniel Hernández-Castillo, F.D. 2015. Changes in the production of salicylic and jasmonic acid in potato plants (Solanum tuberosum) as response to foliar application of biotic and abiotic inductors. American Journal of Plant Sciences. 6(11): 1785-1791. https://doi.org/10.4236/ ajps.2015.611179.

Gutiérrez-Martínez, P.B., Torres-Morán, M.l., Romero-Puertas, M.C., Casas-Soles, J., Zarazúa-Villaseñor, P. Sandoval-Pinto, E., Ramírez-Hernández, B.C. 2020. Assessment of antioxidant enzymes in leaves and roots of Phaseolus vulgaris plants under cadmium stress. Biotecnia. 22(2):110-118. https://doi. org/10.18633/biotecnia.v22i2.1252
Gho, Y.S., Kim, S.j., Jung, K.H. 2020. Phenylalanine ammonia-lyase family is closely associated with response to phosphate deficiency in rice. Genes and Genomics. 42:67-76. https:// doi.org/10.1007/s13258-019-00879-7

Glas, J.J., Schimmel, B.C.J., Alba, J.M., Escobar, B. R., Schuurink, R.C., Kant, M.R. 2012. Plant glandular trichomes as targets for breeding or engineering of resistance to herbivores. International Journal of Molecules Sciences.13 (12):1707717103. https://doi.org/10.3390/ijms131217077

Jain, D., Khurana J.P. 2018. Role of Pathogenesis-Related (PR) Proteins in plant defense mechanism. In: Singh A., Singh I. (eds) Molecular aspects of plant-pathogen interaction. Springer, Singapore. https://doi.org/10.1007/978-981-107371-7_12

Jun, S-Y., Sattler, S.A., Cortez, G.S., Vermerris, W., Sattler, S.E., Kang, $\mathrm{CH}$. 2018. Biochemical and structural analysis of substrate specificity of a Phenylalanine Ammonia-Lyase. Plant Physiology. 176(2). 1452-1468. https://doi.org/10.1104/ pp.17.01608

Khan, M.A., Khan, S.A., Waheed, U., Raheel, M., Khan, Z., Alrefaei, A.F., Alkhamis, H.H. 2021. Morphological and genetic characterization of Fusarium oxysporum and its management using weed extracts in cotton. Journal of King Saud University -Science. 33(101299):1-7. https://doi. org/10.1016/j.jksus.2020.101299

Khanna, K., Jamwal, V.L., Kohli, S.K. Gandhi, S.G., Ohri, P., Bhardwaj, R., Wijaya, L., Alymeni, M.N. Ahmad, P. 2019. Role of plant growth promoting bacteria (PGPRs) as biocontrol agents of Meloidogyne incognita through improved plant defense of Lycopersicon esculentum. Plant and Soil. 436:325345. https://doi.org/10.1007/s11104-019-03932-2

Latha, P., Karthikeyan, M., Rajeswari, E. 2019. Endophytic bacteria: Prospects and applications for the plant disease management. In: Ansari, R., Mahmood, I. (eds) Plant Health Under Biotic Stress. Springer, Singapore. https://doi. org/10.1007/978-981-13-6040-4_1

Leslie, J. F., Summerell, B. A. 2006. The Fusarium Laboratory Manual. Blackwell Publishing. Kansas Agricultural Experiment Station, Manhattan. 388p.

Moosa, A., Farzand, A., Sahi, S.T., Khan, S.A. 2017. Transgenic expression of antifungal pathogenesis-related proteins against phytopathogenic fungi-15 years of success. Israel Journal of Plant Science. 32(1-2):38-54. https://doi.org/10.1 080/07929978.2017.1288407

Muthukumar, A., Udhayakumar, R., Naveenkumar, R. 2017. Role of bacterial endophytes in plant disease control. In: Maheshwari, D., Annapurna, K. (eds) Endophytes: crop productivity and protection. Sustainable Development and Biodiversity. 16. Springer, Cham. https://doi. org/10.1007/978-3-319-66544-3_7

Nasir, H. A., Abbasi, S., Sharifi, R., Jamali, S. 2018. The effect of biocontrol agents consortia against Rhizoctonia root rot of common bean Phaseolus vulgaris. Journal of Crop Protection. 7(1):73-85 URL: http://jcp.modares.ac.ir/article3-4575-en.html

Nicholson T. P., Rudd B. A.M., Dawson M., Lazarus C.M., Simpson T.J., Cox R.X. 2001. Design and utility of oligonucleotide gene probes for fungal polyketide synthases. Chemistry and Biology. 8:157-178. https://doi.org/10.1016/s10745521(00)90064-4 


\section{Castro-del Ángel et al: Biotecnia / XXIII (3): 167-174 (2021)}

Oladzad, A., Zitnick-Anderson, K., Jain, S., Simons, K., Osorno, J. M., McClean, P. E., Pasche, J. S. 2019. Genotypes and genomic regions associated with Rhizoctonia solani resistance in common bean. Frontiers in Plant Science, 10:1-14 https:// doi:10.3389/fpls.2019.00956

Pandey, V.P., Awasthi, M., Singh, S., Tiwari, S., Dwivedi, U.N. 2017. A Comprehensive review on function and application of plant peroxidases. Biochemistry and Analytical Biochemistry. 6(1):1-16. https://doi.org/10.4172/2161-1009.1000308

Pingping, S., Jianchao, C., Xiaohui, J., Wenhui, W. 2017. Isolation and characterization of Bacillus Amyloliquefaciens L-1 for biocontrol of pear ring rot. Horticultural Plant Journal. 3(5): 183-189. https://doi.org/10.1016/j.hpj.2017.10.004

Rais, A., Jabeen, Z., Shair, F., Hafeez, F.Y., Hassan, M.N. 2017. Bacillus spp., a bio-control agent enhances the activity of antioxidant defense enzymes in rice against Pyricularia oryzae. PLoS ONE. 12(11) e0187412:1.17. https://doi. org/10.1371/journal.pone.0187412

Rodríguez, P. A.T., Ramírez, A.M. A.y Cárdenas, T. R. M. 2006. Efecto de la quitosana en la inducción de la actividad de enzimas relacionadas con la defensa y protección de plántulas de arroz (Oryza sativa L.) contra Pyricularia grisea Sacc. Revista Mexicana de Fitopatología. 24 (1): 1-7. Disponible en: http:// www.redalyc.org

Sahni, S., Prasad, B.D. Management of collar rot disease using vermicompost and a PGPR strain Pseudomonas sp. and their effect on defense-related enzymes in chickpea. 2020. Indian Phytopathology. 73: 301-311. https://doi.org/10.1007/ s42360-020-00203-4

Singha, I.M., Kakoty, Y., Unni, B.G., Das, J., Kalita, M.C. 2016. Identification and characterization of Fusarium sp. using ITS and RAPD causing fusarium wilt of tomato isolated from Assam, North East India. Journal of Genetic Engineering and Biotechnology. 14(1): 99-105. https://doi.org/10.1016/j. jgeb.2016.07.001

Sneh, B., Burpee, L., Ogoshi, A. 1991. Identification of Rhizoctonia species. American Phytopatological Society, St. Paul, MN, USA. $133 \mathrm{p}$.
Shoaib, A., Shezad, A., Javaid, A., Akhtar, S., Awan, Z.A. 2019. Evaluation of biocontrol strategies and its synergistic interaction permitting the chickpea plant to trigger the appropriate defense responses against Sclerotium rolfsii. Biologia (Lahore, Pakistan). 65(2):329-334.

Singh, P., Singh, J., Ray, S., Rajput, R. S., Vaishnav, A., Singh, R. K., Singh, H. B. 2020. Seed biopriming with antagonistic microbes and ascorbic acid induce resistance in tomato against Fusarium wilt. Microbiological Research. 237 (126482). https://doi.org/10.1016/j.micres.2020.126482

Tamosiune, I., Baniulis, D., Stanys, V. 2017. Role of endophytic bacteria in stress Tolerance of agricultural plants: Diversity of microorganisms and molecular mechanisms. In: Kumar, V., Kumar, M., Sharma, S., Prasad, R. (eds) Probiotics in Agroecosystem. Springer, Singapore. https://doi. org/10.1007/978-981-10-4059-7_1

Trotel, A. P., Couderchet M., Biagianti S., Aziz, A. 2007. Characterization of new bacterial biocontrol agents Acinetobacter, Bacillus, Pantoea and Pseudomonas spp. mediating grapevine resistance against Botrytis cinerea. Environmental and Experimental Botany. 64: 21-32. https:// doi.org/10.1016/j.envexpbot.2007.12.009

Yanti, Y., Hamid, H., Yaherwandi, R. 2021. Biological control of Sclerotium rolfsii on tomato seedlings using Bacillus spp. consortium. IOP Conference Series: Earth and Environmental Science. 741(012063): 1-5. https://doi.org/10.1088/17551315/741/1/012063

Yedidia, N. Benhamou \& I. Chet. 1999. Induction of defense reponses in Cucumber plants (Cucumis sativs L.) by the biocontrol agent Trichoderma harzanium. Applied Environmental Microbiology. 65(3):1061-1070. https://doi. org/0.1128/AEM.65.3.1061-1070.1999

Zhen, H.X., DeGang, Z. 2017. Research progress in regulation and control mechanism of phenylalanine ammonia lyase in plants. Guizhou Agricultural Sciences. 45 (4):16-20. URL : http://www.gznykx.org.cn/Jweb_gznykx/... 